\title{
EMPOWERMENT OF WOMEN DOCTORATES IN ENGINEERING
}

\author{
Mrs. S. V. Devika ${ }^{1}$, Dr. K. Sarat Kumar ${ }^{2}$, Dr. K. CH. Srikavya ${ }^{3}$ \\ ${ }^{1}$ Department of ECE, Hyderabad Institute of Technology and Management, Hyderabad \\ ${ }^{2,3}$ Department of ECE, KL University, Vijayawada. \\ ${ }^{1}$ devikasv.ece@hitam.org \\ ${ }^{2}$ kksarat@gmail.com \\ ${ }^{3}$ kavyakorada@gmail.com
}

\begin{abstract}
Traditionally, women in India have shied away from engineering and related fields. However recent trends suggest that more and more females are participating in the growing technology sector in India. Although this new interest open doors for new opportunities for females as well as Indian economy, research on women $\mathrm{PhD}$ 's in engineering in India still remains scarce whereas on the contrary underrepresentation of women in the sciences and engineering has been examined in greater depth in many other countries. Since the period of doctoral education crucially clashes with women's age of marriage and family in India, special provisions such as part-time $\mathrm{PhD}$ 's, more flexibility in terms of time period for completion, government scholarships and funding etc may be useful in increasing their participation. Bringing in all these opportunities for women can help to develop skills that allow them to make decisions and influence community change.
\end{abstract}

This paper brings out the problems faced by the women in engineering and research fields to pursue their PhD's and presents various motivational schemes for empowerment of women doctorates who are pursuing PhD's in India.

Keywords: Engineering, Doctorates, Government Funding, Empowerment.

\section{Mrs. S. V. Devika ${ }^{1}$}

Department of ECE, Hyderabad Institute of Technology and Management, Hyderabad

${ }^{1}$ devikasv.ece@hitam.org

\section{Introduction}

Compared to other developed countries, the Indian culture is entirely different. Gender discrimination and family background have traditionally effected education and confidence of women in India. According to a survey conducted among girls pursuing engineering and women graduates, most of the girls discontinue education after engineering. A very little percentage of them are found going for higher education till M. Tech/M.E/MS levels and finally settle with job.

While the findings are not new and are also available in various published sources, but the study has come up with a fresh round of discussion about women competency and their role in engineering. It is evident that they are not getting deserved positions in the corporate world, still many companies have not been able to retain more women employees for job on regular basis. It is also a known fact that only few top companies have been able to bring out women friendly policies and special provisions to their women employees. Still small and medium enterprises are not taking special care for providing particular services like: flexible time slots, work from home, maternity leave or re-entry in the organization after maternity, equal status and many more. Findings from several studies also show that women discontinue their career at a higher rate than men and suggest that highly qualified women discontinue work voluntarily at some point in their life. Some study reveals that though few steps have been taken and few are in the pipeline, still there is a dearth of policies in the education system to encourage girls for opting science and engineering subjects. Some studies reveal that women are not on the top position due to gender biasness in employment. Women engineers also suffer by pay gaps and are usually marginalized against male colleagues. According to Gender Diversity Benchmark, 2011, India has the lowest national female labor force and the worst leaking pipeline for junior to middle level position women. 
$\square 28.71 \%$ of those at the junior level of the workplace, $\square 14.9 \%$ of those at the middle level

$\square 9.32 \%$ of those at the senior level Engineers in India are enthusiastic about joining software companies.

Engineers at software companies enjoy more benefits: rising salaries, free medical facilities for employees and their family members etc. Software industry's growth is making engineering talent scarce in the country. The skill sets expectation and expertise of Indian engineering graduates is also moving up. So Engineering is an exciting career and paves way to affect local economic well-being. Some researchers have found that a number of factors discourage women from continuing to participate in the engineering field. These include few successful engineering women role models and evidence that the culture of many engineering workplaces are family-unfriendly, with behaviors that overtly reduce or discourage promotion, recognition and rewards

\subsection{Why So FEW?}

Academic research on this topic is prolific, with three themes emerging from the literature. First, the notion that men are mathematically superior and innately better suited to engineering fields than women are remains a common belief with a large number of articles addressing cognitive gender differences as an explanation for the small numbers of women. The second theme revolves around girls' lack of interest in this field and the third theme involves the workplace, with issues ranging from work-life balance to bias. Lack of freedom is also one of the major limitations for women to complete their higher education.

Women are scared about research and higher education in their career because of some specific reasons:

1) Lack of guidance in their area of research

2) Family conditions \& other moral obligations of women such as responsibility as a mother

3) Financial support for higher education

4) Gender discrimination

An informal environment in engineering is also a major concern and cannot be studied without taking into consideration the status of women in society. The nature of Indian society is vastly different from the Western society. India is a patriarchy with certain differences (to the western patriarchy) that have affected interaction between men and women. Religion, culture and patrifocal ideology demonstrate concern with the protection of female sexuality, which has implications for male-female interaction. Restrictions on the latter have also constricted women's education. Even though there are differences of caste, class, and religion, "there is a thread of cultural unity which allows one to talk of a Hindu woman"

With female enrolments growing at all levels of higher education, still doctoral degrees have been one area where men have continued to dominate. The majority for women in doctoral degrees is not seen in all disciplines. Only 22 percent of engineering doctorates in 2008-09 were awarded to women, and only 27 percent in mathematics and computer science. Further, the rate of increase in doctoral awards for women outpaces that for men in all disciplines. Over all, women became the majority of new doctorate recipients in a year in which their numbers increased by 6.1 percent while male numbers increased by 1.0 percent.

\section{Challenges facing by the women scholors}

This study focused on questions that addressed students' perceptions about the main problems encountered during their doctoral studies, their well-being, and study engagement. The $\mathrm{PhD}$ student survey, conducted in May 2006, consisted of both Likert-type statements and openended questions. The survey was sent to all doctoral students in the faculties of Engineering Technology. The contact information of the students was collected from the student register database.

In the present part of the study, the $\mathrm{PhD}$ students' perceptions of typical challenges and problems within the $\mathrm{PhD}$ process were explored with the following open-ended questions: "Doctoral students may face many problematic situations and challenges during the $\mathrm{PhD}$ process. What kind of problematic situations, questions, or challenges do you find typical of the $\mathrm{PhD}$ process?"

Table 1 show that $\mathrm{PhD}$ students' study engagement and well-being were measured. Questionnaire has served in various contexts, such as teacher education and medical education, and it was modified to fit the $\mathrm{PhD}$ context.

A Likert scale ranging from 1 (do not agree) to 5 (fully agree) was used for all questions except the one-item stress scale, whose alternatives varied from 1 (not at all) to 5 (very much).

\begin{tabular}{|l|l|}
\hline Scale & Items included in the scale \\
\hline Stress & $\begin{array}{l}\text { "Stress means a situation in which a } \\
\text { person feels tense, restless, nervous or } \\
\text { anxious, or is unable to sleep because } \\
\text { his/her mind is troubled all the time." } \\
\text { Do you feel this kind of stress these days? }\end{array}$ \\
\hline Exhaustion & $\begin{array}{l}\text { I feel exhausted. } \\
\text { My workload is often too high. } \\
\text { Doctoral studies are too stressful for } \\
\text { me. } \\
\text { I worry about my thesis in my free } \\
\text { time. }\end{array}$ \\
& $\begin{array}{l}\text { I often fear that I will fail in my doctoral } \\
\text { studies. } \\
\text { I am stressed out by the workload, } \\
\text { deadlines, and competition in doctoral } \\
\text { studies. }\end{array}$ \\
\hline
\end{tabular}




\begin{tabular}{|l|l|}
\hline & $\begin{array}{l}\text { I must often force myself to work on my } \\
\text { thesis. }\end{array}$ \\
\hline $\begin{array}{l}\text { Lack of } \\
\text { interest }\end{array}$ & $\begin{array}{l}\text { It is difficult for me to find meaning in } \\
\text { my doctoral studies. } \\
\text { I am not motivated by the content of my } \\
\text { studies. }\end{array}$ \\
\hline
\end{tabular}

Table 1: The items included in the questionnaire

\section{Informal Environment}

There are no formal rules that discriminate against women. Both men and women research scholars completely disagree that professors are partial in grading or judging females. Women disagree much more than men that professors have lower expectations from women than men. Both disagree that the women faculty are biased in the favor of women scholars, although, women disagree much more than men.

Thus, the women and men researchers are convinced that their performance is correctly evaluated. Yet, $56.4 \%$ (44 of 78) women scholars agreed that women have to work harder than men in order to prove themselves, while only about $26 \%$ (21 of 81 ) of the male scholars agreed with the statement. A general belief in meritocracy and impartiality masks the problems at the informal level. Informal interaction is problematic for women partly due to a lack of critical mass.

\section{Process of improving and retention of women in Engineering fields:}

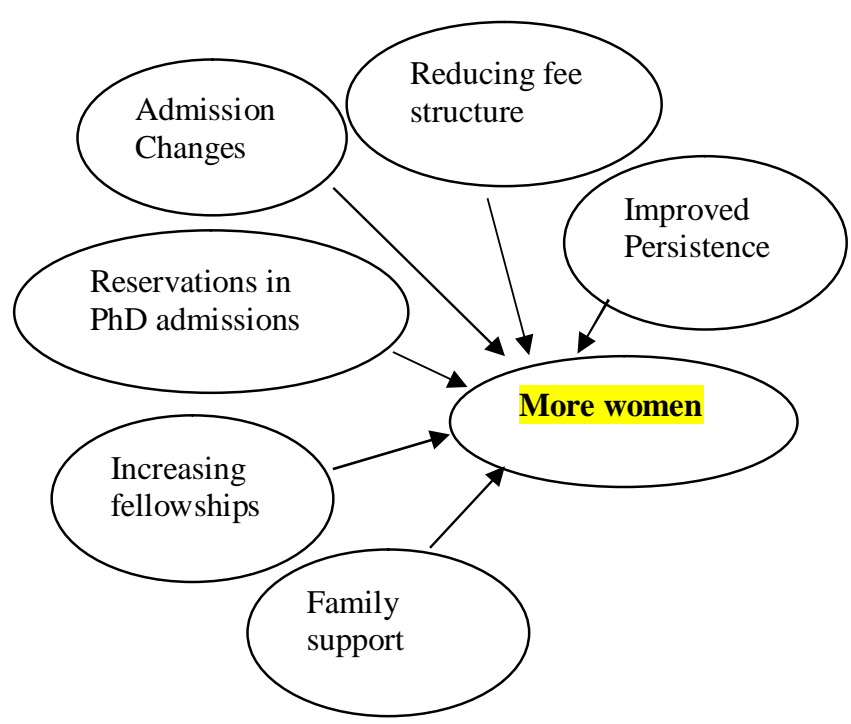

Fig. 1 Process of retention of women doctorates

4.1 Spread the word about girls' and women's achievements in math and science: The stereotype that men are better than women in engineering field can affect women performance, how they judge their performance, and their aspirations. The more people hear this kind of information, the harder it becomes for them to believe that boys and men are better in these areas.

4.2 Teach girls that intellectual skills, including spatial skills, are acquired: Teach girls that every time they work hard and learn something new, their brains form new connections, and over time they become smarter. Teach girls that passion, dedication, and self-improvement, not simply innate talent, are the road to achievement and contribution. Praise girls for their effort rather than their intelligence. Communicate to girls that seeking challenges, working hard, and learning from mistakes are valuable.

4.3 Talented and gifted programs should send the message that they value growth and learning: Talented and gifted programs can benefit students by sending the message that students are in these programs not because they have been bestowed with a "gift" of great ability but because they are advanced in certain areas and the program will help them further develop their abilities. Consider changing the name of talented and gifted programs to "challenge" or "advanced" programs to emphasize more of a growth mindset and less of a fixed mindset

4.4 Help women recognize their career-relevant skills: women are less likely than men to interpret their academic successes in engineering \& Technology as an indication that they have the skills necessary to become a successful engineer, physicist, or computer scientist.

4.5 Encourage girls to see their success in high school math and science for what it is: Not Just as a requirement for going to college but also an indication that they have the skills to succeed in a whole range of science and engineering professions.

\section{Government Funding}

Government of India came forward with many schemes to uplift women graduates in engineering. There are many Government funding agencies like DST, CSIR, AICTE, UGC, ISRO etc. All thanks to the government for providing such funding schemes to uplift women's career to complete their $\mathrm{PhD}$ in a given specific time. The below mentioned are few such government schemes

\subsection{DST women scientist scheme}

Women constitute an important section of the workforce. However, the present situation of a large number of wellqualified women scientists who due to various circumstances have been left out of the S\&T activities needs to be addressed. The problems faced are several but, significantly, most often the "break in their careers" arises out of motherhood and family responsibilities. The option 
for revival of their profession is presently unavailable due to restrictions in age and qualification and no system at present addresses these issues.

The "Women Scientists Scheme (WOS)" has been evolved in this context, by the Department of Science and Technology (DST) for providing opportunities to women scientists and technologists between the age group of 30-50 years who desire to return to mainstream science and work as bench-level scientists. Through this endeavour of the department, a concerted effort is made to give women a strong foothold into the scientific profession, help them reenter into the mainstream and provide a launch pad for further forays into the field of science and technology, both from the point of view of pure science and its application to societal development.

Under this scheme, women scientists are encouraged to pursue research in frontier areas of science and engineering, on problems of societal relevance and to take up S\&T-based internship followed by self-employment.

Women scientists having a Ph.D. in Basic or Applied Sciences, M.Tech. or MD/MS, DM/MCH in Medical Sciences from recognized Universities and those who are pursuing $\mathrm{PhD}$ can apply up to the age of 50 years. The amount of fellowship for such candidates will be Rs. 40,000/- PM.

\subsection{SERB (Science and Engineering Research Board)}

SERB supports research in frontier areas of Science and Engineering. A regular faculty / researcher in an academic / research institution can seek research support to carry out his/her research. Board also gives special attention to young scientists below the age of 35 years (relaxable by 5 years in the case of SC/ST/OBC, woman and physically handicapped category) to undertake independent research in newly emerging and frontier areas of science and engineering.

5.3 Department of Scientific and Industrial Research (DSIR): The Department of Scientific and Industrial Research (DSIR) is a part of the Ministry of Science and Technology, which was announced through a Presidential Notification, dated January 4, 1985. The Department of Scientific and Industrial Research (DSIR) has a mandate to carry out the activities relating to indigenous technology promotion, development, utilization and transfer. The Technology Promotion, Development and Utilization (TPDU) Programmes are directed towards meeting the specific needs of industry and are of particular relevance in the present context. Programmes and activities under the scheme are centered around promoting industrial R\&D, development and commercialization of technologies, acquisition, management and export of technologies, promotion of consultancy capabilities, etc.

5.4 Indian Space Research Organisation (ISRO) Department of Space: To conduct research and development activities in the relevant areas of space science,

$$
\text { ב्ञ }
$$

application and technology at the universities and academic institutions in the country. Also, to establish interactions between scientists working at ISRO and academic institutions to carry out joint research and educational activities of interest to the Indian Space Programme.

5.5 INSPIRE Faculty Scheme (DST): INSPIRE Faculty Scheme opens up an 'Assured Opportunity for Research Career (AORC)' for young researchers in the age group of 27-32 years. It is expected to augment high quality scientific manpower in scientific and educational institutions. It provides attractive opportunities to young achievers for developing independent scientific profiles and intends helping them emerge as S\&T leaders in the long term. The Scheme offers contractual research positions. It provides career opportunities, but it is not a guarantee for tenure positions after 5 years.

\section{Conclusion}

This paper concludes that women are facing many problems and are coming across lot of limitations in completing their PhD's. A significant number of them are discontinuing their education before completion. Even in such limiting conditions, this research concludes that with the help of available government schemes, women can complete their $\mathrm{PhD}$ independently. Apart from DST, SERB there are many other schemes offered and can be availed through various government platforms.

\section{Acknowledgement}

I acknowledge Government of India, especially Department of Science and Technology, DST, New Delhi and Science and Engineering Research Board (SERB) and all other government funding agencies for providing with the valuable information on schemes for the women. I express my sincere gratitude to the Management Sri. Prashanth Arutla, Principal Dr. SVS Rama Krishnam Raju and Head of the Department of ECE, Prof. T. Pullaiah of Hyderabad Institute of Technology and Management, Hyderabad for their encouragement and support to publish this paper.

\section{References}

[1] Eisenhart, M. 1994. Women scientists and the norm of gender neutrality at work. Journal of Women and Minorities in Science and Engineering 1 (3): 193-207.

[2] Etzkowitz, H., C. Kemelgor, and B. Uzzi. 2000. Athena unbound: The advancement of women in science and technology. Cambridge: Cambridge University Press. Fox, M. F. 2000. 
[3] Organizational environments and doctoral degrees awarded to women in science and engineering departments. Women Studies Quarterly 28: 47-61.

[4] Godbole, R., N. Gupte N., and S. Rao. 2002. Women in physics, meeting reports. Current Science 83: $359-61$. Gupta, N., and A. K. Sharma. 2002.

[5] Women academic scientists in India. Social Studies of Science 32 (5-6): 901-15.

[6] Science, Technology, \& Human Values Volume 32 Number 5 September 2007 507-533 (C) 2007 Sage Publications10.1177/0895904805303200.http://sth.sagepub. com hosted at http://online.sagepub.com
[7] Why So Few? Women in Science,Technology, Engineering, and Mathematics Catherine Hill, Ph.D. Christianne Corbett Andresse St. Rose, Ed.D.

[8] Challenges of Becoming a Scholar: A Study of Doctoral Students' Problems and Well-Being, International Scholarly Research Network ISRN Education Volume 2012,Article ID 934941, 12 pages doi:10.5402/2012/934941

[9] www.dst.gov.in

[10] www.serb.gov.in

[11] www.drdo.gov.in

[12] www.isro.gov.in 